\title{
Paulinella chromatophora - rethinking the transition from endosymbiont to organelle
}

\author{
Eva C.M. Nowack* \\ Department of Biology, Heinrich-Heine-Universität Düsseldorf, Universitätsstrasse 1, 40225 Düsseldorf, Germany
}

\begin{abstract}
Eukaryotes co-opted photosynthetic carbon fixation from prokaryotes by engulfing a cyanobacterium and stably integrating it as a photosynthetic organelle (plastid) in a process known as primary endosymbiosis. The sheer complexity of interactions between a plastid and the surrounding cell that started to evolve over 1 billion years ago, make it challenging to reconstruct intermediate steps in organelle evolution by studying extant plastids. Recently, the photosynthetic amoeba Paulinella chromatophora was identified as a much sought-after intermediate stage in the evolution of a photosynthetic organelle. This article reviews the current knowledge on this unique organism. In particular it describes how the interplay of reductive genome evolution, gene transfers, and trafficking of host-encoded proteins into the cyanobacterial endosymbiont contributed to transform the symbiont into a nascent photosynthetic organelle. Together with recent results from various other endosymbiotic associations a picture emerges that lets the targeting of host-encoded proteins into bacterial endosymbionts appear as an early step in the establishment of an endosymbiotic relationship that enables the host to gain control over the endosymbiont.
\end{abstract}

Keywords: organellogenesis; plastid evolution; endosymbiosis; cyanobacterium; photosynthesis; chromatophore; protein targeting; Rhizaria

\section{The evolution of plastids}

Primary plastids, the photosynthetic organelles of Plantae (i.e. green algae/land plants, red algae, and glaucophytes) evolved more than 1 billion years ago (gya) through the endosymbiotic uptake of a cyanobacterium by a heterotrophic protist host [1-3]. Photosynthetic carbon fixation from the newly acquired plastid relieved the host from its dependency on the continuous uptake of organic carbon molecules from the environment. In addition to photosynthetic carbon fixation, plastids provide other beneficial metabolic functions to the plant/algal cell such as the assimilation of ammonia and sulfate into amino acids [4], assembly of iron-sulfur clusters [5], de novo biosynthesis of fatty acids [6], isopentenyl diphosphate (IPP) [7], and aromatic amino acids [8]; and they contribute to pathways that are distributed over several compartments, such as photorespiration and biosynthesis of pyrimidines and folates [9-11].

Evolution of plastids was accompanied by a strong reduction of the size of the cyanobacterial genome and the transfer of thousands of cyanobacterial genes into the host nuclear genome, a process termed endosymbiotic gene

\footnotetext{
*Email: e.nowack@uni-duesseldorf.de
}

Handling Editor: Andrzej Bodył transfer (EGT) $[12,13]$. This resulted in proteins localized to the cyanobacterium, now a full-fledged plastid, being synthesized in the cytoplasm and then imported into the plastid through a sophisticated import machinery (the TIC/ TOC complex; short for: translocon of the inner and outer chloroplast membranes) targeted by N-terminal transit peptides [14]. A multitude of solute transporters underlie the intricate metabolic crosstalk between plastid and the surrounding cell by controlling fluxes of metabolites and ions through the double membrane system that delimits the plastid [15-17]. Signaling pathways from and to the plastid communicate environmental cues and the metabolic and developmental status of different compartments within the plant/algal cell $[18,19]$. An interplay of eukaryote- and cyanobacterium-derived proteins coordinate plastid division with the host cell cycle [20].

Following the establishment of primary plastids in Plantae, photosynthetic ability spread to other eukaryotic lineages through secondary endosymbioses [21,22]. In secondary endosymbioses a red or green alga served as an endosymbiont, leading to the establishment of secondary plastids in heterokontophytes (stramenopiles), cryptophytes, haptophytes, dinoflagellates, apicomplexa, chlorarachniophytes, and euglenophytes. In most cases the only remnant of the eukaryotic symbiont is one or two extra membranes that surround the secondary plastid. The nuclear genome of the 
eukaryotic endosymbiont was reduced and genes important to operate the plastid were transferred into the host nucleus. However, in the cryptophytes and chlorarachniophytes, a residual eukaryotic nucleus is still present in the periplastidial compartment $[23,24]$.

Since plastids became dependent on the import of nuclearencoded proteins for metabolism, growth, and proliferation, they cannot be regarded as independent organisms, but rather as semiautonomous parts of the host cell. Thus, the endosymbiont and surrounding eukaryote merged into one chimeric organism. This makes the endosymbiotic acquisition of organelles one of the most transformative forces of eukaryotic evolution. Understanding the molecular mechanisms that underlie this transformation process is fascinating in its own right. Additionally, it might gain an important practical significance for engineering custom-made organelles with novel functions in the context of synthetic biology. However, it is challenging to deduce the intermediate steps in the evolution of the complex and highly optimized interactions between the plastid and the surrounding plant/algae cell from studies of extant primary plastids that are the product of over 1 billion years of evolutionary tinkering. Therefore, it is of pivotal interest to identify cyanobacteria-derived photosynthetic organelles at earlier stages of evolution and dissect their biology. Recently, the photosynthetic amoeba Paulinella chromatophora (Fig. 1a,b), was identified as such a much sought-after intermediate stage [25-27].

\section{Paulinella chromatophora}

Paulinella chromatophora was first described in 1895 by Robert Lauterborn from an old riverbed of the upper river Rhine in Germany [28,29] and has been reported since from freshwater (and sometimes brackish [30]) habitats around the world, including sites in Austria [31], Switzerland [32], the Netherlands [33], Great Britain [34], the United States [35], Japan [36], and Canada [37]. Its preferred habitat seems to be shady sediments of freshwater bodies that are microaerophilic, rich in organic compounds, with increased salinity, and relatively low $\mathrm{pH}$ [38]. Like its heterotrophic marine relatives (Paulinella carsoni, P. gigantica, P. indentata, $P$. intermedia, $P$. lauterborni, $P$. multipora, $P$. ovalis, and P. suzukii) [37], P. chromatophora is a thecate amoeba that lives inside an oval-shaped, lucid shell (or "theca") consisting of five rows of silicate scales with a terminal aperture (or "mouth opening") for the naked filopodia that enable the cells to perform sluggish movements (Fig. 1b).

In contrast to its heterotrophic relatives that feed on bacteria, including cyanobacteria $[39,40]$, digestive vacuoles have never been observed in P. chromatophora [28,32,33,41], suggesting that the amoeba has dispensed with phagotrophic nutrition. Instead P. chromatophora carries two prominent blue-green sausage-shaped photosynthetic units in its cytoplasm that seem to support a phototrophic lifestyle and are referred to as "chromatophores" or "cyanelles". Already Lauterborn indicated in his original description that chromatophores are morphologically very distinct from typical plastids, but resemble cyanobacteria - in particular members of the genus Synechococcus. In contrast to free-living Synechococcus spp. which are rod-shaped cells approximately $0.5-1.5 \mu \mathrm{m}$ long, chromatophores are approximately $15-20 \mu \mathrm{m}$ long with a 3.5-4 $\mu \mathrm{m}$ diameter. Electron microscopic studies of $P$. chromatophora by Ludwig Kies in 1974 substantiated the similarity to cyanobacteria on an ultrastructural level [41]: the chromatophores, which are located in the host cytoplasm are surrounded by two membranes and a peptidoglycan wall between inner and outer membrane. The latter is interpreted as a host-derived vesicle by Kies. In their cytoplasm, chromatophores contain concentrically arranged thylakoids covered with phycobilisomes (the light-harvesting complexes of cyanobacteria) and polyhedral carboxysomes (proteinaceous micro-compartments involved in the carbon concentration mechanisms in cyanobacteria). Despite their morphological similarity to cyanobacteria, chromatophores cannot survive independently of their host.

Within the host, chromatophores are strictly vertically inherited [33]. Before cell division, the mother cell assembles a new theca from silica scales that are produced in cytoplasmic vacuoles. Filopodia are used to arrange the secreted scales into a new theca [42]. The daughter cell, including one of the chromatophores, is then squeezed through the mouth


Fig. 1 Paulinella chromatophora. a,b Different focal planes of micrographs of $P$. chromatophora (differential interference contrast). c Schematic representation of cell division in P. chromatophora. 
opening into the new theca $[33,42]$. The chromatophores then grow in length taking on a horseshoe shape and finally divide by binary fission, restoring the original state of two chromatophores per cell (Fig. 1c).

$\mathrm{H}^{14} \mathrm{CO}_{3}^{-}$labeling experiments by Kies and Kremer confirmed in 1979 that $P$. chromatophora photosynthetically assimilates radiocarbon. After $3 \mathrm{~h}$ of labeling in the light, radiocarbon had been incorporated into a wide variety of assimilates including glucose, organic phosphates, amino acids, TCA cycle intermediates, and lipids. However, over $40 \%$ of the radiolabel ended up in the ethanol-insoluble fraction, probably as proteins and polyglucans [43].

\section{Chromatophores originated independently of plastids}

Initially, a rigorous dissection of $P$. chromatophora biology was hampered by the inability to establish a culture. All experiments had to be performed on individuals collected from the environment. It was not until 1990 that the establishment of a clonal culture of $P$. chromatophora in the lab of Michael Melkonian from an isolate from a small pond in the Spessart Forest, Germany (strain M 0880 and later strain CCAC 0185, a further purified subisolate thereof) [38] and advances in DNA sequencing technology allowed for exploring this unusual protist in more depth.

Sequence analysis of the $18 \mathrm{~S}$ rDNA placed the $P$. chromatophora host cell within the Euglyphidae [44], an order of filose testate amoebae within the Cercozoa, Rhizaria $[45,46]$. Aside from P. chromatophora, there is one other photosynthetic clade among the Cercozoa: the chlorarachniophytes. These net-forming amoebae, which are only distantly related to the Euglyphida, obtained a plastid by secondary endosymbiosis of a green alga [47]. This raised the question whether the chromatophore of $P$. chromatophora was also product of a secondary endosymbiosis, possibly involving a glaucophyte (whose plastids contain a peptidoglycan wall and concentrically arranged thylakoid membranes with phycobilisomes) [48], or whether it arose independently of plastids.

Phylogenetic analyses of the ribosomal and the carboxysomal operon of the chromatophore and numerous cyanobacteria and plastids placed the chromatophore at the base of the Synechococcus/Prochlorococcus/Cyanobium clade of cyanobacteria, distant from plastids [25,49]. This group of cyanobacteria is also referred to as $\alpha$-cyanobacteria because they contain a type $1 \mathrm{~A}$ ribulose-1,5-bisphosphate carboxylase/oxygenase (RubisCO), in contrast to the remaining $\beta$-cyanobacteria and plastids (with the exception of red algal plastids $[50,51])$ that contain a type $1 \mathrm{~B}$ RubisCO [49]. The $a$-cyanobacterial origin of the chromatophore was later confirmed by phylogenetic analyses of multiple protein coding genes [36,52] and genomic data (see below). Taken together, these data yielded overwhelming evidence that the chromatophore originated independently from plastids. Since $P$. chromatophora was the first - and so far only - permanently photosynthetic eukaryote that evolved its photosynthetic ability independently of the event that gave rise to the plastids, this finding resulted in considerable scientific interest in P. chromatophora.

\section{Reductive genome evolution in the chromatophore}

To understand in which way the chromatophore was integrated into the metabolic networks of the host cell and to determine whether its genome had been reduced with respect to free-living cyanobacteria, the chromatophore genome sequence of $P$. chromatophora CCAC 0185 was completed in 2008 [27]. With a size of only $1.02 \mathrm{Mbp}$ comprising 867 protein-coding genes, the chromatophore genome had been reduced to about $1 / 3$ of the size of genomes of basally branching free-living a-cyanobacteria (e.g. Synechococcus WH5701 with a genome size of approximately $3 \mathrm{Mbp}$ and 3346 protein-coding genes). Nevertheless, the chromatophore genome is still about 5-10 times larger than a typical plastid genome, which rarely exceed $200 \mathrm{kbp}$ and generally encode less than 200 genes. Genome reduction in the chromatophore went along with an increase in $\mathrm{A}+\mathrm{T}$ content to $62 \%$, as frequently observed for bacterial endosymbionts (for a discussion of this phenomenon see e.g. [53]). Gene losses were most pronounced for genes without assigned functions, likely constituting a reservoir for functional responses to environmental changes and, thus, possibly no longer needed in the homogeneous intracellular environment. Also capabilities for DNA repair and regulation of transcription were limited. Furthermore, biosynthetic capabilities have been clearly reduced: pathways for the biosynthesis of several amino acids (Glu, Arg, His, Try, and Met) and cofactors $\left(\mathrm{NAD}^{+}\right.$, riboflavine, thiamine, biotin, cobalamine, pantothenate, and coenzyme A) were missing. For other amino acids and purine nucleotides, precursors cannot be formed, although later biosynthetic steps are retained. Moreover, all genes encoding enzymes of the TCA cycle, which provides primary building blocks for the synthesis of important cellular compounds, are missing.

Conversely, the chromatophore seems to be much more autonomous than plastids. While in plants, plastid division proteins of cyanobacterial origin are encoded on the nuclear genome, most of the cell-division genes commonly found in a-cyanobacteria $(f t s Z, f t n 2, \min C, \min D, \min E, c d v 1$, and $c d v 2$ ) are encoded on the chromatophore genome. All genes essential for light harvesting, the function of photosystem (PS) I and II, the cytochrome $b_{6} / f$ complex, and the F-type ATPase, are present on the chromatophore genome. Only two genes that encode low molecular weight subunits of PSI, $p s a E$ and $p s a K$, were lost. Besides its photosynthetic machinery, the chromatophore retained other biosynthetic capabilities that are potentially beneficial for the host, such as assimilatory sulfate reduction, biosynthesis of fatty acids, IPP, cofactors such as lipoic acid and folate, and some amino acids (Ala, Val, Ile, and Leu).

The gene complement encoded on the chromatophore genome suggests an intricate metabolic crosstalk between host and chromatophore. This would require efficient metabolite transport systems in both directions. However, transport capabilities encoded on the chromatophore genome are also strongly reduced (e.g. uptake systems for any form of nitrogen are missing). This suggests that nuclear-encoded transport systems are involved in metabolite exchange between host and chromatophore. In agreement with this idea, it has been reported that the majority of plastid solute transporters in 
Plantae were derived from the host. Authors hypothesized that the insertion of host-derived transporters into the plastid envelope membranes provided a mechanism to rapidly establish metabolic control over the evolving plastid [54].

\section{Age of the chromatophore and speciation}

Determining the age of an endosymbiotic association without direct fossil record is inherently difficult. However, using a Bayesian relaxed molecular clock calibrated with multiple calibration points from the microfossil record (dinoflagellates, diatoms, and coccolithophorids), divergence between $P$. chromatophora and the non-photosynthetic relative Euglypha rotunda was estimated to be 200 mya, delimiting the maximum age of the chromatophore [55]. The minimum age of the chromatophore was estimated to be 60 mya, based on timing estimates for the complete disintegration of inactivated genes in endosymbiotic bacteria [27]. An interesting question concerns the diversity that evolved within the photosynthetic Paulinella population within the 60-200 million years since chromatophore acquisition.

In 2009, a second P. chromatophora strain (FK01 or NIES2635) was brought into culture by Takeshi Nakayama from an isolate from Daigo, Ibaraki Prefecture, Japan [36]. FK01 differs from CCAC 0185 with regard to cell size, and number and fine-structure of the silica scales. Phylogenetic analyses of the 16S rDNA of the chromatophores of CCAC 0185 and FK01 plus four further P. chromatophora individuals collected from the environment indicate monophyly of all chromatophores that form two distinct sister clades, one containing CCAC 0185, the other FK01 [36]. Additionally, 18S rDNA and actin phylogenies support monophyly of the CCAC 0185 and FK01 host cells [36]. This phylogenetic pattern is most easily explained by a single origin of chromatophores followed by diversification. Based on morphological and molecular differences observed between CCAC 0185 and FK01 it is likely that these two strains represent distinct species [36]. The establishment of strain FK01 opened the exciting possibility to study divergent evolution of this endosymbiotic association after uptake of the cyanobacterium.

The completion of the chromatophore genome sequence from strain FK01 revealed a genome with a size of $0.977 \mathrm{Mbp}$, which is slightly smaller than the chromatophore genome of CCAC 0185 (1.02 Mbp). Gene order appears to be largely conserved with respect to CCAC 0185. Nevertheless, 27 genes that are encoded in FK01 are absent from CCAC 0185, whereas 39 genes encoded in CCAC 0185 are absent from FK01 [56]. The majority of these differentially lost genes seem to be outright lost rather than transferred into the nucleus.

\section{Cyanobacterial genes in the nuclear genome of $P$. chromatophora}

From the chromatophore genome sequences alone it was not clear in which way the host cell compensates for lost chromatophore functions. An important question was whether in P. chromatophora some of the genes that have been lost from the chromatophore were transferred to the host nuclear genome, similar to the evolution of plastids. To answer this question, cDNA libraries from strain FK01 and CCAC 0185 were generated and analyzed. The first two likely chromatophore-derived genes identified in the nuclear transcripts of strain FK01 were genes coding for low molecular weight subunits of PSI, PsaE [57] and PsaI [56]. The corresponding chromatophore genes were missing in FK01. A broader survey of EGT in P. chromatophora CCAC 0185 revealed more than 30 nuclear genes of possible chromatophore origin [58]. Most of these EGT genes encoded very short proteins with a function in photosynthesis or light-acclimation of the cell, including the low molecular weight subunits of PSI - PsaE and two divergent copies of PsaK. The predicted functions strongly suggested that at least a subset of the products encoded by EGT genes function within the chromatophore. A G+C content similar to host genes but distinct from the A+T-rich chromatophore genes, the presence of spliceosomal introns, and polyA tails in the mRNAs confirmed that EGT genes were located in, and expressed from the nuclear genome [56-58].

Intriguingly, also 10 genes of $\beta$-cyanobacterial or unclear cyanobacterial origin were identified in the transcriptome of CCAC 0185 [58]. These genes had more diverse metabolic functions and did not share the bias towards short genes. Whether or not their products function within the chromatophore is unclear. In phagotrophic protists, horizontal gene transfer (HGT) from food organisms is well documented [59-61]. Thus, these genes presumably represent HGTs from cyanobacteria that served as food sources to P. chromatophora, before it gave up phagotrophy.

Larkum et al. [62] argued that organellogenesis does not necessarily involve only one host engulfing a single target organism, but that a host might form a series of transient endosymbioses before a stable relationship is finally achieved. In their "shopping bag model", the resulting organelle is regarded as a chimera of products collected through EGT from different predecessors [62]. In the same line, recently, genes derived from probably co-housed Chlamydia, intracellular bacterial pathogens, were proposed to play an important part in the establishment of primary plastids in the Plantae [63-66]. Both P. chromatophora cultures available for the transcriptome analyses contained co-cultured bacteria (however, no free cyanobacteria). Some of these co-cultured bacteria live attached to $P$. chromatophora cells and seem to promote the growth of the amoebae (own observations); hence, they are difficult to remove from the culture. As a consequence, the transcriptome data derived from these non-axenic cultures could not easily be analyzed for HGT from bacteria other than cyanobacteria. Nevertheless, HGT from other bacteria might have contributed to forge the nuclear genome of $P$. chromatophora.

Our upcoming genomic/transcriptomic studies from a recently established axenic $P$. chromatophora culture indicate that several bacterial genes might play critical roles in integrating the chromatophore. Thus, it would be reasonable to extend the shopping bag model [62] from genes collected from transient symbionts to genes obtained from pathogens and prey organisms that all might contribute to establishing an endosymbiont and integrating it into a eukaryotic host as an organelle. 


\section{A mechanistic view on gene transfers}

EGT from plastids and mitochondria is thought to involve the direct movement of DNA following organelle degradation [67-70] and non-homologous end joining at doublestrand breaks in the nucleus [71]. In P. chromatophora, a stable number of two chromatophores per cell established, and no developmental stages are known that involve the degradation of chromatophores. Damage and lysis of one of the chromatophores would probably represent a rather traumatic event that occurs very rarely and is even more rarely survived. Thus, if indeed lysis of organelles/endosymbionts is necessary for EGT to occur, it is possible that most EGTs in P. chromatophora either predate the acquisition of chromatophores or originate from a time when the number of chromatophores per cell was not fixed yet. This view is supported by the fact that also in a heterotrophic $P$. ovalis-like cell a nuclear gene of $\alpha$-cyanobacterial origin was identified encoding a diaminopimelate epimerase [72].

It is plausible to assume that the symbiotic association between host and $\alpha$-cyanobacterium established gradually from a predator/prey relationship (Fig. 2). Delaying digestion of the cyanobacterial prey initially would have increased the food supply for the amoeba by allowing its prey to grow and proliferate, using $\mathrm{CO}_{2}$ and light energy, i.e. nutrient and energy sources that could not be directly used by the host. This scenario, would have given plenty of opportunity to transfer genes from lysed prey/early symbiotic cells and a "practice ground" for establishing protein targeting. However, there are indications that some of the EGTs found in P. chromatophora might be more recent events. Two examples are the nuclear genes csoS4A and psaI: (i) in the case of $\operatorname{csoS} 4 A$, encoding a short carboxysomal shell polypeptide, there is - in addition to an expressed nuclear copy - a second copy of the gene in the chromatophore genome. While the amino acid sequence of the chromatophore-encoded copy is highly conserved with respect to cyanobacterial orthologues, the nuclear copy is relatively divergent [58]; (ii) in the case of psaI that has been identified in the nuclear transcripts of FK01 (see above), the gene is still identifiable in the FK01 chromatophore genome but has been silenced by two nonsense mutations [56]; in CCAC 0185 , the chromatophore-encoded copy of psaI is still intact. These two cases illustrate the different possible fates of genes that managed to get expressed from the nuclear genome following EGT: as long as a protein encoded by the nuclear copy did not achieve targeting to its site of function, the gene is initially under strongly reduced functional constraints and hence prone to accumulate mutations. This can lead to the nuclear gene either evolving a new function or becoming non-functional (i.e. a pseudogene) and finally erode [73]. If the gene product, however, - probably much more rarely - becomes targeted to its site of function, loss of either copy could be fixed by selection (or stochastically).

Doolittle described very convincingly that even if achieving expression and correct targeting appears to be highly unlikely for a transferred gene, over evolutionary times, the repeated possibility for EGTs after organelle/endosymbiont lysis leads to a "gene transfer ratchet" by which most organellar genes functionally integrate in the nucleus [60]. For $p s a I$ and $\operatorname{csoS} 4 A$ this gene transfer ratchet seems to be caught in the act, with psaI getting fixed in the nucleus and $c s o S 4 A$ likely being in the process of obtaining a new function or getting lost again from the nucleus either stochastically or because it failed to obtain the correct targeting information.

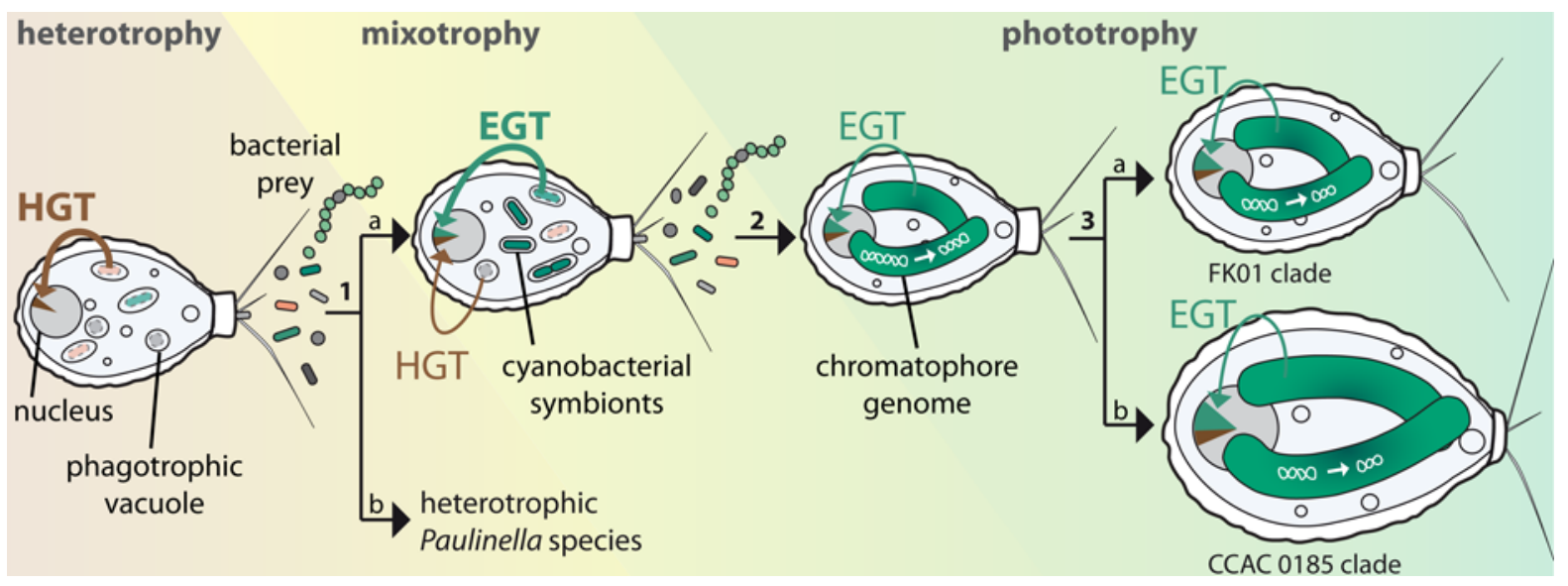

Fig. 2 Proposed model for the evolution of phototrophy in P. chromatophora. Heterotrophic and phototrophic Paulinella species share a common bacterivorus predecedor (left). 1a A mixotrophic cell evolved by initially delaying digestion of a particular type of $\alpha$-cyanobacteria and exploiting their photosynthetic ability. During this stage EGTs and HGTs were possible. The host started to insert transporters into the symbiont-surrounding membranes and target protein into the bacterial symbionts. 1b Heterotrophic Paulinella species did not acquire the ability to house cyanobacterial endosymbionts. 2 As the host cell continues to target proteins into the endosymbiont and regulate metabolic fluxes between the cytoplasm and the endosymbiont, it gains control over the endosymbiont's growth and division. This underpins a stable vertical inheritance. Efficient metabolite exchange makes phagotrophy dispensable (although organic solutes might still be taken up from the environment) and functional constraints relax for hundreds of chromatophore genes leading to massive chromatophore genome reduction. Lysis of chromatophores becomes less frequent and the rate of EGT slows down. 3a,b Divergent evolution results in different phototrophic Paulinella species (represented by strain CCAC 0185 and FK01). Speciation is accompanied by continued chromatophore genome reduction that leads to differential gene losses (and probably differential EGTs) in CCAC 0185 vs. FK01. Colored sections in the nucleus represent contribution of HGT (brown) and EGT (green) to the nuclear genome, the thickness of the arrows represents prevalence of the particular type of gene transfer during different evolutionary stages. At which point the number of chromatophore-surrounding membranes was reduced from 3 to 2 is uncertain. 
It is tempting to speculate that fixation of the nuclear copy of a transferred gene is not purely stochastic. Rather, by giving the host transcriptional and translational control over some cellular compounds that are critical to endosymbiont function, coordination of host and endosymbiont metabolism, growth, and proliferation is facilitated and the association between the two partners becomes stabilized.

Another interesting observation was that several EGT genes were present in multiple, in sequence divergent copies, suggesting that the genes duplicated - likely after transfer into the nuclear genome. The largest gene family of EGT genes with at least 15 copies encode a class of proteins designated high-light inducible proteins, or Hlips. These small proteins are proposed to be the progenitors of the light-harvesting chlorophyll $\mathrm{a}, \mathrm{b}$ binding proteins in green algae and land plants and have been shown to be critical for light acclimation of cyanobacteria $[74,75]$.

\section{Import of nuclear-encoded proteins into the chromatophore}

The observation that EGT genes were conserved in amino acid sequence while adjusting their codon usage to the host and acquiring spliceosomal introns strongly suggests that the cellular function of EGT gene products was retained. Experimental evidence that EGT genes in P. chromatophora indeed yield products which function in the chromatophore came from immunogold analyses using antibodies raised against $P$. chromatophora PsaE and compositional analysis of PSI isolated from P. chromatophora CCAC 0185 [26]. Furthermore, autoradiography of resolved PSI subunits, isolated from $P$. chromatophora cells that were radiolabeled in the presence of chloramphenicol or cycloheximide (that selectively inhibit protein biosynthesis in chromatophore and cytoplasm, respectively), demonstrated that PsaE, PsaK1, and PsaK2 are synthesized in the cytoplasm of the amoeba.

Various possible routes to import protein into the chromatophore have been proposed [76]. Some genes that evolved in Plantae into components of the TIC/TOC complex are conserved on the chromatophore genome (e.g. Toc12, Tic21, and Tic32) and it has been speculated that the corresponding gene products might be involved in protein import into the chromatophore; e.g. a good candidate for a protein transport channel in the inner chromatophore membrane is the homologue of Tic21 [76]. However, homologues of other essential TIC/TOC subunits are missing. Most importantly Omp85, the cyanobacterial homologue of Toc75, which forms the major protein translocating pore in the outer chloroplast membrane, is neither encoded on the chromatophore genome nor was it found in nuclear transcripts of CCAC 0185. Detection of a significant amount of PsaE in the Golgi by immunogold analysis suggested that protein import into the chromatophore involves vesicular transport through the Golgi [26]. Surprisingly, however, all three imported proteins seem to be devoid of cleavable N-terminal signal peptides (SPs) that usually govern co-translational protein import into the endoplasmic reticulum [58]. Also bioinformatic analyses showed that there is no common pre-sequence feature associated with the EGT gene sequences [58,77].
Understanding the mechanism that targets nuclearencoded proteins into the chromatophore in more detail is difficult because no genetic transformation system is available for P. chromatophora, which would enable experimental exploration of targeting signals. The expression of transgenes in P. chromatophora might be difficult to establish because the cells grow extremely slowly [78], the cells do not grow on solid media (own observation), and the prominent silica theca might impede delivery of a transgene into the $P$. chromatophora nucleus.

\section{Paulinella chromatophora as a model for early plastid evolution?}

Evolution is not necessarily repetitive. Thus, an important question is in how far chromatophores recapitulate the same or similar steps as early primary plastids. Comparing chromatophores and primary plastids, it is fascinating that several 100s of millions of years after the establishment of plastids in the Plantae, a symbiosis involving a cyanobacterium and a protist host that are both very different from the partner organisms that gave rise to the Plantae, converged into a strikingly similar result (a photosynthetic organelle surrounded by two envelope membranes; genome reduction; EGT; protein import; control of metabolite fluxes by host-encoded transport systems). Despite the astonishing similarities between chromatophores and primary plastids, details of the molecular mechanisms employed to integrate the cyanobacterial symbiont might differ.

In primary plastids the outer membrane is believed to be mainly homologous to the outer cyanobacterial membrane but has acquired some eukaryotic features [79]. In contrast, the outer chromatophore membrane might be rather host-derived based on its morphology and the lack of genes encoding porins on the chromatophore genome; however also a chimeric nature is possible (for a discussion of this issue see [80]). Although the exact route of protein import into chromatophores is still elusive, the localization of chromatophore-targeted proteins in the Golgi implies that - other than in primary plastids, where most proteins pass the outer envelope membrane through a translocator pore - the outer chromatophore membrane is likely passed through vesicle fusion. Intriguingly, also in primary plastids a few specific proteins were found to be imported through a TIC/TOC-independent, Golgi-mediated pathway [81,82]. This finding led to the question whether a protein secretion mechanism pre-existing in the host could have been recruited initially for protein targeting to the evolving plastid and was only later replaced by the TIC/TOC system [83]. However, other authors argued that gradual evolution of the TIC/TOC multi-subunit translocon from a simpler system composed of cyanobacterial components is the more parsimonious and thus the more likely scenario, because it would not require the evolution of SPs and subsequently their modification into plastid transit peptides for plastid-targeted proteins; in this case, Golgi-dependent protein import would be regarded as a derived feature [79]. Also, phylogenetic analyses of proteins targeted into primary plastids via the endomembrane system 
supported the view of Golgi-dependent protein import as an evolutionary derived feature [84].

However, irrespective of the mechanism by which nuclearencoded proteins traffic into the chromatophore and whether or not a similar targeting mechanism has been used by evolving primary plastids, $P$. chromatophora has the potential to provide important insights germane to organelle evolution. These insights concern in particular: (i) early stages in the merging of genetic systems in response to endosymbiotic interactions; (ii) contribution of genes obtained by other organisms through HGT to the integration of an evolving organelle; (iii) molecular mechanisms that can provide a eukaryotic host with control over growth and division of an endosymbiont early on; (iv) origin and characteristics of transport systems for exchange of metabolites with the surrounding cell; $(\boldsymbol{v})$ acquisition of regulatory and detoxifying capacity that allow a previously heterotrophic host to control gene expression/translation in response to light signals and/ or redox state of the evolving organelle and to counteract increased levels of oxidative stress that are associated with a phototrophic lifestyle.

There are other examples of highly reduced cyanobacterial endosymbionts, such as Candidatus Atelocyanobacterium thalassa living symbiotically with a haptophyte alga [85] or the "spheroid bodies" in rhopalodiacean diatoms $[86,87]$. However, these symbionts lost their ability to perform oxygenic photosynthesis and their main function is thought to be nitrogen fixation. Hence, the chromatophore of $P$. chromatophora is the closest model to an early primary plastid found so far.

\section{Transitions from endosymbionts to organelles}

Until recently, the difference between organelle and endosymbiont appeared to be clear cut: while endosymbionts might lose many genes and depend on their hosts for providing metabolites, an endosymbiont codes for and synthesizes all its own proteins; the import of functional protein was regarded as an exclusive feature of canonical organelles, i.e. mitochondria and plastids $[88,89]$. However, with growing knowledge on bacterial endosymbionts, it becomes increasingly difficult to pinpoint when exactly the transition into an organelle occurs (for a discussion see e.g. $[26,83,90-96])$. There is accumulating evidence that, in fact, in many endosymbiotic systems host-encoded proteins get targeted into the bacterial partners that have been regarded as endosymbionts and not as organelles for decades.

Facultative endosymbiotic nitrogen-fixing bacteria (Rhizobia), living in the nodules of the legume Medicago truncatula, were reported to import plant-encoded peptides that evolved from effectors of the plant's innate immune system [97]. In the weevil Sitophilus spp., a host-derived antimicrobial peptide was found to get selectively targeted into relatively recently acquired (20 mya) $\gamma$-proteobacterial endosymbionts that reside in specialized symbiont-harboring cells, termed "bacteriocytes" [98]. In both cases, the immune system-derived peptides trigger dramatic morphological and physiological changes upon import into the endosymbiont [97,98]. And finally, the pea aphid Acyrthosiphon pisum contains the $\gamma$-proteobacterial endosymbiont Buchnera aphidicola in bacteriocytes. Although the symbionts are transovarially transmitted (i.e. Buchnera cells are exocytosed from maternal bacteriocytes and endocytosed by syncytial blastulae) and thus have access to the host germ line [99], functional EGTs have not been found [100]. Nevertheless, A. pisum acquired several genes from other bacteria via HGT [100,101]. The mechanism of HGT in aphids is not known, but would likely involve other bacteria reaching the blastula and getting lysed there. Expression of some of these bacteria-derived genes was found to be highly upregulated in bacteriocytes [100]. Using antibodies raised against the predicted protein sequence of one of these bacterium-derived nuclear A. pisum genes, $r l p A 4$, Nakabachi et al. show that this protein is specifically targeted into B. aphidicola [94]. The function of this protein is not yet known. In all three examples, endosymbionts are enclosed in host-derived membrane vesicles and targeting of the proteins into the symbionts is initiated through the secretory pathway mediated by $\mathrm{N}$-terminal SPs. Interestingly, also protein import into complex plastids is initiated through the secretory pathway, mediated by N-terminal SPs [22].

Although a large diversity of bacterial endosymbionts has been described and there is a plethora of genomic data available (for reviews see e.g. [53,102-105]), most endosymbiotic associations have not been studied at the biochemical level. Therefore, whether or not host-encoded protein gets targeted into the symbionts is unknown. However, genomes of several bacterial endosymbionts in various insects are reduced to organellar sizes (e.g. Hodgkinia cicadicola, $0.144 \mathrm{Mbp}$; Carsonella ruddii, 0.160 Mbp; Sulcia muelleri, 0.246 Mbp) [106-108] and in some cases genome reduction involves the loss of genes involved in DNA replication, transcription, and translation (i.e. functions that occur in the endosymbiont but that are not readily compensated for at the metabolite level) [109]. This finding strongly suggests that an existence as autoreduplicating units is impossible without the import of functional protein from the host.

Since eukaryotic host cells were found to target functional proteins into - even facultative - endosymbionts, the criterion of import of functional protein does not seem to be valid to differentiate organelles from endosymbionts. Furthermore, the transfer of symbiont genes into the nucleus of the host is often regarded as a first required step in the origin of an import apparatus for nuclear-encoded proteins and thus as a required step in the origin of organelles $[88,89]$. This view is problematic since the examples discussed above demonstrate that protein import is not subordinate to preceding EGT but can apply to proteins deriving from HGTs or the host itself. In fact, with the findings described in this text section, it seems possible that the import of host-encoded proteins into endosymbiotic bacteria - rather than being the final result of a long co-evolution - represents an early step in the establishment of an endosymbiotic relationship. Targeting of protein into the endosymbiont might enable the host to control and manipulate the endosymbiont according to its needs. So, theoretically, it would be feasible that essential functions that are lost, due to genome reduction in an endosymbiont, are replaced by cytoplasmically-synthesized proteins that are imported into the endosymbiont, but that 
are encoded by genes that do not originate from the endosymbiont. Irrespective of the origin of the imported protein, conceptually this system would be the same as an organelle.

Thus, a good line to draw between an endosymbiont and an organelle seems to be the moment when the endosymbiont - as a consequence of gene loss - becomes dependent for survival and proliferation on the import of nuclear-encoded proteins. These proteins can be derived from EGT, HGT, or the host itself. In this situation, the symbiont cannot be regarded as an independent organism anymore, but is genetically integrated into the host organism and thus has to be regarded as a part of the host. Further criteria that an organelle has to fulfill are vertical inheritance and providing a benefit to the host. If we regard these three criteria as defining an organelle, chromatophores clearly have to be addressed as organelles, even though the coding capacity of their genome is still much larger than the one of plastids and mitochondria. It is possible that some other bacterial entities that are so far regarded as endosymbionts (e.g. some nutritional endosymbionts in insects) will have to be re-classified as early stages of symbiont-derived organelles; but, before this classification can be made, further data on protein import and the cellular functions of imported proteins are required.

\section{Summary and future directions}

Although P. chromatophora was described over 100 years ago, initiating a rigorous dissection of its biology was only possible after establishment of clonal cultures. Phylogenetic analyses of these cultures clearly established an independent and more recent origin of the chromatophore with respect to primary plastids. After integration of the chromatophore, divergent evolution resulted in at least two different photosynthetic $P$. chromatophora lineages - likely representing distinct species. Genomic and biochemical studies characterized the chromatophore as a bona fide, but early stage photosynthetic

\section{Acknowledgments}

I am grateful to Dr. Michael Melkonian, Dr. Ru Zhang, Dr. Andrzej Bodył as the editor, and to three anonymous reviewers for proof-reading the manuscript and providing many helpful comments. Work in this area is supported in our lab by Deutsche Forschungsgemeinschaft Grant NO 1090/1-1.

\section{Competing interests}

No competing interests have been declared.

\section{References}

1. Dorrell RG, Howe CJ. What makes a chloroplast? Reconstructing the establishment of photosynthetic symbioses. J Cell Sci. 2012;125(8):1865-1875. http://dx.doi.org/10.1242/jcs.102285

2. Dyall SD, Brown MT, Johnson PJ. Ancient invasions: from endosymbionts to organelles. Science. 2004;304(5668):253-257. http://dx.doi. org/10.1126/science.1094884

3. Parfrey LW, Lahr DJG, Knoll AH, Katz LA. Estimating the timing of early eukaryotic diversification with multigene molecular clocks. Proc Natl Acad Sci USA. 2011;108(33):13624-13629. http://dx.doi. org/10.1073/pnas.1110633108

4. Weber A, Flügge UI. Interaction of cytosolic and plastidic nitrogen organelle. This makes $P$. chromatophora the closest model for early primary plastids identified so far and hence a unique model to explore the transformation of a cyanobacterium into a genetically integrated photosynthetic organelle.

The nuclear genome sequence of $P$. chromatophora would represent a valuable informational foundation to explore mechanism and dynamics of EGT and the contribution of genes acquired by HGT to chromatophore integration. Experimental determination of the full extent of protein import into the chromatophore would foster our understanding of the molecular mechanisms through which integration occurs. It would be important to determine $(\boldsymbol{i})$ whether import is restricted to short polypeptides like the three PSI subunits that have been described so far; (ii) whether also HGT and host-derived proteins get imported; (iii) what functions are fulfilled by imported proteins; (iv) and whether imported proteins share common structural characteristics that might provide clues about a common targeting mechanism.

Targeting of functional host-encoded proteins into bacterial endosymbionts is likely more frequent than currently assumed. In all bacterial endosymbionts in which protein import has been described (plus secondary plastids), the endomembrane system seems to be involved in targeting. Thus, it is reasonable to assume that endomembrane systemmediated protein targeting into bacterial endosymbionts represents a general mechanism by which a eukaryotic host cell gains control over an endosymbiont at relatively early stages in the establishment of an endosymbiotic relationship.

In the light of recent data, the import of functional hostencoded protein appears not to be a suitable criterion for defining an organelle anymore. Thus, the following criteria were suggested as defining an organelle: $(\boldsymbol{i})$ dependence on import of host-encoded protein for growth and proliferation; (ii) vertical inheritance; and (iii) benefit for the host. In order to find out if more bacterial endosymbionts have reached the status of early organelles, biochemical studies of further endosymbiotic associations would be necessary.

metabolism in plants. J Exp Bot. 2002;53(370):865-874. http://dx.doi. org/10.1093/jexbot/53.370.865

5. Balk J, Lobréaux S. Biogenesis of iron-sulfur proteins in plants. Trends Plant Sci. 2005;10(7):324-331. http://dx.doi.org/10.1016/j. tplants.2005.05.002

6. Wang Z, Benning C. Chloroplast lipid synthesis and lipid trafficking through ER-plastid membrane contact sites. Biochem Soc Trans. 2012;40(2):457-463. http://dx.doi.org/10.1042/BST20110752

7. Lichtenthaler HK, Schwender J, Disch A, Rohmer M. Biosynthesis of isoprenoids in higher plant chloroplasts proceeds via a mevalonateindependent pathway. FEBS Lett. 1997;400(3):271-274. http://dx.doi. org/10.1016/S0014-5793(96)01404-4

8. Herrmann KM, Weaver LM. The shikimate pathway. Annu Rev Plant Physiol Plant Mol Biol. 1999;50(1):473-503. http://dx.doi.org/10.1146/ annurev.arplant.50.1.473

9. Hanson AD, Gregory III JF. Synthesis and turnover of folates in plants. Curr Opin Plant Biol. 2002;5(3):244-249. http://dx.doi.org/10.1016/ S1369-5266(02)00249-2

10. Witz S, Jung B, Fürst S, Möhlman T. De novo pyrimidine nucleotide synthesis mainly occurs outside of plastids, but a previously undiscovered nucleobase importer provides substrates for the essential 
salvage pathway in Arabidopsis. Plant Cell. 2012;24(4):1549-1559. http://dx.doi.org/10.1105/tpc.112.096743

11. Maurino VG, Peterhansel C. Photorespiration: current status and approaches for metabolic engineering. Curr Opin Plant Biol. 2010;13(3):248-255. http://dx.doi.org/10.1016/j.pbi.2010.01.006

12. Martin W, Rujan T, Richly E, Hansen A, Cornelsen S, Lins T, et al. Evolutionary analysis of Arabidopsis, cyanobacterial, and chloroplast genomes reveals plastid phylogeny and thousands of cyanobacterial genes in the nucleus. Proc Natl Acad Sci USA. 2002;99(19):1224612251. http://dx.doi.org/10.1073/pnas.182432999

13. Timmis JN, Ayliffe MA, Huang CY, Martin W. Endosymbiotic gene transfer: organelle genomes forge eukaryotic chromosomes. Nat Rev Genet. 2004;5(2):123-135. http://dx.doi.org/10.1038/nrg1271

14. Schleiff E, Becker T. Common ground for protein translocation: access control for mitochondria and chloroplasts. Nat Rev Mol Cell Biol. 2011;12(1):48-59. http://dx.doi.org/10.1038/nrm3027

15. Flügge UI, Häusler RE, Ludewig F, Gierth $M$. The role of transporters in supplying energy to plant plastids. J Exp Bot. 2011;62(7):2381-2392. http://dx.doi.org/10.1093/jxb/erq361

16. Weber AP. Solute transporters as connecting elements between cytosol and plastid stroma. Curr Opin Plant Biol. 2004;7(3):247-253. http:// dx.doi.org/10.1016/j.pbi.2004.03.008

17. Pick TR, Weber APM. Unknown components of the plastidial permeome. Front Plant Sci. 2014;5:410. http://dx.doi.org/10.3389/ fpls.2014.00410

18. Chi W, Sun X, Zhang L. Intracellular signaling from plastid to nucleus. Annu Rev Plant Biol. 2013;64(1):559-582. http://dx.doi.org/10.1146/ annurev-arplant-050312-120147

19. Barkan A. Expression of plastid genes: organelle-specific elaborations on a prokaryotic scaffold. Plant Physiol. 2011;155(4):1520-1532. http:// dx.doi.org/10.1104/pp.110.171231

20. Miyagishima S. Mechanism of plastid division: from a bacterium to an organelle. Plant Physiol. 2011;155(4):1533-1544. http://dx.doi. org/10.1104/pp.110.170688

21. Archibald JM. The puzzle of plastid evolution. Curr Biol. 2009;19(2):R81-R88. http://dx.doi.org/10.1016/j.cub.2008.11.067

22. Gould SB, Waller RF, McFadden GI. Plastid evolution. Annu Rev Plant Biol. 2008;59(1):491-517. http://dx.doi.org/10.1146/annurev. arplant.59.032607.092915

23. Douglas S, Zauner S, Fraunholz M, Beaton M, Penny S, Deng LT, et al. The highly reduced genome of an enslaved algal nucleus. Nature. 2001;410(6832):1091-1096. http://dx.doi.org/10.1038/35074092

24. Gilson PR, Su V, Slamovits CH, Reith ME, Keeling PJ, McFadden GI. Complete nucleotide sequence of the chlorarachniophyte nucleomorph: nature's smallest nucleus. Proc Natl Acad Sci USA. 2006;103(25):9566-9571. http://dx.doi.org/10.1073/pnas.0600707103

25. Marin B, Nowack ECM, Melkonian M. A plastid in the making: evidence for a second primary endosymbiosis. Protist. 2005;156(4):425432. http://dx.doi.org/10.1016/j.protis.2005.09.001

26. Nowack ECM, Grossman AR. Trafficking of protein into the recently established photosynthetic organelles of Paulinella chromatophora. Proc Natl Acad Sci USA. 2012;109(14):5340-5345. http://dx.doi. org/10.1073/pnas.1118800109

27. Nowack ECM, Melkonian M, Glöckner G. Chromatophore genome sequence of Paulinella sheds light on acquisition of photosynthesis by eukaryotes. Curr Biol. 2008;18(6):410-418. http://dx.doi.org/10.1016/j. cub.2008.02.051

28. Lauterborn R. Protozoenstudien. Z Wiss Zool. 1895;59:537-544.

29. Melkonian M. Robert Lauterborn (1869-1952) and his Paulinella chromatophora. Protist. 2005;156(2):253-262. http://dx.doi.org/10.1016/j. protis.2005.06.001

30. Pankow H. Paulinella chromatophora Lauterb., eine bisher nur im Süßwasser nachgewiesene Thekamöbe, in den Boddengewässern des Darß and des Zingst (südliche Ostsee). Arch Protistenkd. 1982;126(3):261263. http://dx.doi.org/10.1016/S0003-9365(82)80036-5

31. Geitler L. Bemerkungen zu Paulinella chromatophora. Zool Anz. 1927;72:333-334.
32. Penard E. Notes sur quelques Sarcodinés - 12. Paulinella chromatophora Lauterborn. Rev Suisse Zool. 1905;13:585-616.

33. Hoogenraad HR. Zur Kenntnis der Fortpflanzung von Paulinella chromatophora Lauterb. Zool Anz. 1927;72:140-150.

34. Brown JM. Freshwater rhizopods from the English lake district. Zool J Linn Soc. 1910;30(201):360-368. http://dx.doi. org/10.1111/j.1096-3642.1910.tb02142.x

35. Lackey JB. Some fresh water protozoa with blue chromatophores. Biol Bull. 1936;71(3):492-497.

36. Yoon HS, Nakayama T, Reyes-Prieto A, Andersen RA, Boo SM, Ishida KI, et al. A single origin of the photosynthetic organelle in different Paulinella lineages. BMC Evol Biol. 2009;9(1):98. http:// dx.doi.org/10.1186/1471-2148-9-98

37. Nicholls KH. Six new marine species of the genus Paulinella (Rhizopoda: Filosea, or Rhizaria: Cercozoa). J Mar Biol Assoc UK. 2009;89(07):1415-1425. http://dx.doi.org/10.1017/S0025315409000514

38. Melkonian M, Surek B. Famous algal isolates from the Spessart forest (Germany): the legacy of Dieter Mollenhauer. Algol Stud. 2009;129(1):123. http://dx.doi.org/10.1127/1864-1318/2009/0129-0001

39. Hannah F, Rogerson A, Anderson OR. A description of Paulinella indentata n. sp. (Filosea: Euglyphina) from subtidal coastal benthic sediments. J Eukaryot Microbiol. 1996;43(1):1-4. http://dx.doi. org/10.1111/j.1550-7408.1996.tb02464.x

40. Johnson PW, Hargraves PE, Sieburth JM. Ultrastructure and ecology of Calycomonas ovalis Wulff, 1919, (Chrysophyceae) and its redescription as a testate rhizopod, Paulinella ovalis n. comb. (Filosea: Euglyphina). J Protozool. 1988;35(4):618-626. http://dx.doi. org/10.1111/j.1550-7408.1988.tb04160.x

41. Kies L. Electron microscopical investigations on Paulinella chromatophora Lauterborn, a thecamoeba containing blue-green endosymbionts (Cyanelles). Protoplasma. 1974;80(1):69-89.

42. Nomura M, Nakayama T, Ishida K. Detailed process of shell construction in the photosynthetic testate amoeba Paulinella chromatophora (Euglyphid, Rhizaria). J Eukaryot Microbiol. 2014;61(3):317-321. http://dx.doi.org/10.1111/jeu.12102

43. Kies L, Kremer BP. Function of cyanelles in the thecamoeba Paulinella chromatophora. Naturwissenschaften. 1979;66(11):578-579. http:// dx.doi.org/10.1007/BF00368819

44. Bhattacharya D, Helmchen T, Melkonian M. Molecular evolutionary analyses of nuclear-encoded small subunit ribosomal RNA identify an independent rhizopod lineage containing the Euglyphina and the Chlorarachniophyta. J Eukaryot Microbiol. 1995;42(1):65-69. http:// dx.doi.org/10.1111/j.1550-7408.1995.tb01541.x

45. Cavalier-Smith T, Chao EEY. Phylogeny and classification of phylum Cercozoa (Protozoa). Protist. 2003;154(3-4):341-358. http://dx.doi. org/10.1078/143446103322454112

46. Moreira D, von der Heyden S, Bass D, López-García P, Chao E, Cavalier-Smith T. Global eukaryote phylogeny: combined small- and large-subunit ribosomal DNA trees support monophyly of Rhizaria, Retaria and Excavata. Mol Phylogenet Evol. 2007;44(1):255-266. http://dx.doi.org/10.1016/j.ympev.2006.11.001

47. McFadden GI, Gilson PR, Hofmann CJ, Adcock GJ, Maier UG. Evidence that an amoeba acquired a chloroplast by retaining part of an engulfed eukaryotic alga. Proc Natl Acad Sci USA. 1994;91(9):3690-3694.

48. Raven JA. Carboxysomes and peptidoglycan walls of cyanelles: possible physiological functions. Eur J Phycol. 2003;38(1):47-53. http:// dx.doi.org/10.1080/0967026031000096245

49. Marin B, Nowack EC, Glöckner G, Melkonian M. The ancestor of the Paulinella chromatophore obtained a carboxysomal operon by horizontal gene transfer from a Nitrococcus-like $\gamma$-proteobacterium. BMC Evol Biol. 2007;7(1):85. http://dx.doi.org/10.1186/1471-2148-7-85

50. Delwiche CF, Palmer JD. Rampant horizontal transfer and duplication of rubisco genes in eubacteria and plastids. Mol Biol Evol. 1996;13(6):873-882.

51. Valentin K, Zetsche K. Structure of the Rubisco operon from the unicellular red alga Cyanidium caldarium: evidence for a polyphyletic origin of the plastids. Mol Gen Genet. 1990;222(2-3):425-430.

52. Yoon HS, Reyes-Prieto A, Melkonian M, Bhattacharya D. Minimal 
plastid genome evolution in the Paulinella endosymbiont. Curr Biol. 2006;16(17):R670-R672. http://dx.doi.org/10.1016/j.cub.2006.08.018

53. McCutcheon JP, Moran NA. Extreme genome reduction in symbiotic bacteria. Nat Rev Microbiol. 2012;10:13-26. http://dx.doi.org/10.1038/ nrmicro2670

54. Tyra HM, Linka M, Weber AP, Bhattacharya D. Host origin of plastid solute transporters in the first photosynthetic eukaryotes. Genome Biol. 2007;8(10):R212. http://dx.doi.org/10.1186/gb-2007-8-10-r212

55. Berney C, Pawlowski J. A molecular time-scale for eukaryote evolution recalibrated with the continuous microfossil record. Proc R Soc B. 2006;273(1596):1867-1872. http://dx.doi.org/10.1098/rspb.2006.3537

56. Reyes-Prieto A, Yoon HS, Moustafa A, Yang EC, Andersen RA, Boo SM, et al. Differential gene retention in plastids of common recent origin. Mol Biol Evol. 2010;27(7):1530-1537. http://dx.doi. org/10.1093/molbev/msq032

57. Nakayama T, Ishida KI. Another acquisition of a primary photosynthetic organelle is underway in Paulinella chromatophora. Curr Biol. 2009;19(7):R284-R285. http://dx.doi.org/10.1016/j.cub.2009.02.043

58. Nowack ECM, Vogel H, Groth M, Grossman AR, Melkonian M, Glöckner G. Endosymbiotic gene transfer and transcriptional regulation of transferred genes in Paulinella chromatophora. Mol Biol Evol. 2011;28(1):407-422. http://dx.doi.org/10.1093/molbev/msq209

59. Andersson JO. Lateral gene transfer in eukaryotes. Cell Mol Life Sci. 2005;62(11):1182-1197. http://dx.doi.org/10.1007/s00018-005-4539-Z

60. Doolittle WF. You are what you eat: a gene transfer ratchet could account for bacterial genes in eukaryotic nuclear genomes. Trends Genet. 1998;14(8):307-311. http://dx.doi.org/10.1016/S0168-9525(98)01494-2

61. Keeling PJ, Palmer JD. Horizontal gene transfer in eukaryotic evolution. Nat Rev Genet. 2008;9(8):605-618. http://dx.doi.org/10.1038/ $\operatorname{nrg} 2386$

62. Larkum AWD, Lockhart PJ, Howe CJ. Shopping for plastids. Trends Plant Sci. 2007;12(5):189-195. http://dx.doi.org/10.1016/j. tplants.2007.03.011

63. Ball S, Colleoni C, Cenci U, Raj JN, Tirtiaux C. The evolution of glycogen and starch metabolism in eukaryotes gives molecular clues to understand the establishment of plastid endosymbiosis. J Exp Bot. 2011;62(6):1775-1801. http://dx.doi.org/10.1093/jxb/erq411

64. Becker B, Hoef-Emden K, Melkonian M. Chlamydial genes shed light on the evolution of photoautotrophic eukaryotes. BMC Evol Biol. 2008;8(1):203. http://dx.doi.org/10.1186/1471-2148-8-203

65. Facchinelli F, Colleoni C, Ball SG, Weber APM. Chlamydia, cyanobiont, or host: who was on top in the ménage à trois? Trends Plant Sci. 2013;18(12):673-679. http://dx.doi.org/10.1016/j.tplants.2013.09.006

66. Huang J, Gogarten J. Did an ancient chlamydial endosymbiosis facilitate the establishment of primary plastids? Genome Biol. 2007;8(6):R99. http://dx.doi.org/10.1186/gb-2007-8-6-r99

67. Fuentes I, Karcher D, Bock R. Experimental reconstruction of the functional transfer of intron-containing plastid genes to the nucleus. Curr Biol. 2012;22(9):763-771. http://dx.doi.org/10.1016/j.cub.2012.03.005

68. Hanekamp T, Thorsness PE. Inactivation of YME2/RNA12, which encodes an integral inner mitochondrial membrane protein, causes increased escape of DNA from mitochondria to the nucleus in Saccharomyces cerevisiae. Mol Cell Biol. 1996;16(6):2764-2771.

69. Lister DL, Bateman JM, Purton S, Howe CJ. DNA transfer from chloroplast to nucleus is much rarer in Chlamydomonas than in tobacco. Gene. 2003;316:33-38. http://dx.doi.org/10.1016/ S0378-1119(03)00754-6

70. Sheppard AE, Ayliffe MA, Blatch L, Day A, Delaney SK, Khairul-Fahmy $\mathrm{N}$, et al. Transfer of plastid DNA to the nucleus is elevated during male gametogenesis in tobacco. Plant Physiol. 2008;148(1):328-336. http:// dx.doi.org/10.1104/pp.108.119107

71. Hazkani-Covo E, Zeller RM, Martin W. Molecular poltergeists: mitochondrial DNA copies (numts) in sequenced nuclear genomes. PLoS Genet. 2010;6(2):e1000834. http://dx.doi.org/10.1371/journal. pgen. 1000834

72. Bhattacharya D, Price DC, Yoon HS, Yang EC, Poulton NJ, Andersen RA, et al. Single cell genome analysis supports a link between phagotrophy and primary plastid endosymbiosis. Sci Rep. 2012;2:356. http://dx.doi.org/10.1038/srep00356

73. Selosse MA, Albert B, Godelle B. Reducing the genome size of organelles favours gene transfer to the nucleus. Trends Ecol Evol. 2001;16(3):135141. http://dx.doi.org/10.1016/S0169-5347(00)02084-X

74. Havaux M, Guedeney G, He Q, Grossman AR. Elimination of highlight-inducible polypeptides related to eukaryotic chlorophyll $a / b$ binding proteins results in aberrant photoacclimation in Synechocystis PCC6803. Biochim Biophys Acta. 2003;1557:21-33. http://dx.doi. org/10.1016/S0005-2728(02)00391-2

75. He Q, Dolganov N, Björkman O, Grossman AR. The high lightinducible polypeptides in Synechocystis PCC6 expression and function in high light. J Biol Chem. 2001;276(1):306-314. http://dx.doi. org/10.1074/jbc.M008686200

76. Bodył A, Mackiewicz P, Stiller JW. Comparative genomic studies suggest that the cyanobacterial endosymbionts of the amoeba Paulinella chromatophora possess an import apparatus for nuclearencoded proteins. Plant Biol. 2010;12:639-649. http://dx.doi. org/10.1111/j.1438-8677.2009.00264.x

77. Mackiewicz P, Bodył A, Gagat P. Possible import routes of proteins into the cyanobacterial endosymbionts/plastids of Paulinella chromatophora. Theory Biosci. 2012;131(1):1-18. http://dx.doi. org/10.1007/s12064-011-0147-7

78. Nowack ECM. Paulinella chromatophora - a model for the acquisition of photosynthesis by eukaryotes [PhD thesis]. Cologne: University of Cologne; 2009.

79. Bodył A, Mackiewicz P, Stiller JW. Early steps in plastid evolution: current ideas and controversies. Bioessays. 2009;31(11):1219-1232. http://dx.doi.org/10.1002/bies.200900073

80. Mackiewicz P, Bodył A. A hypothesis for import of the nuclearencoded PsaE protein of Paulinella chromatophora (cercozoa, rhizaria) into its cyanobacterial endosymbionts/plastids via the endomembrane system. J Phycol. 2010;46(5):847-859. http://dx.doi. org/10.1111/j.1529-8817.2010.00876.x

81. Nanjo Y, Oka H, Ikarashi N, Kaneko K, Kitajima A, Mitsui T, et al. Rice plastidial N-glycosylated nucleotide pyrophosphatase/phosphodiesterase is transported from the ER-Golgi to the chloroplast through the secretory pathway. Plant Cell. 2006;18(10):2582-2592. http://dx.doi.org/10.1105/tpc.105.039891

82. Villarejo A, Burén S, Larsson S, Déjardin A, Monné M, Rudhe $\mathrm{C}$, et al. Evidence for a protein transported through the secretory pathway en route to the higher plant chloroplast. Nat Cell Biol. 2005;7(12):1224-1231. http://dx.doi.org/10.1038/ncb1330

83. Bhattacharya D, Archibald JM, Weber APM, Reyes-Prieto A. How do endosymbionts become organelles? Understanding early events in plastid evolution. Bioessays. 2007;29(12):1239-1246. http://dx.doi. org/10.1002/bies.20671

84. Gagat P, Bodył A, Mackiewicz P. How protein targeting to primary plastids via the endomembrane system could have evolved? A new hypothesis based on phylogenetic studies. Biol Direct. 2013;8(1):18. http://dx.doi.org/10.1186/1745-6150-8-18

85. Thompson AW, Foster RA, Krupke A, Carter BJ, Musat N, Vaulot $\mathrm{D}$, et al. Unicellular cyanobacterium symbiotic with a single-celled eukaryotic alga. Science. 2012;337(6101):1546-1550. http://dx.doi. org/10.1126/science. 1222700

86. Nakayama T, Kamikawa R, Tanifuji G, Kashiyama Y, Ohkouchi N, Archibald JM, et al. Complete genome of a nonphotosynthetic cyanobacterium in a diatom reveals recent adaptations to an intracellular lifestyle. Proc Natl Acad Sci USA. 2014;111(31):11407-11412. http:// dx.doi.org/10.1073/pnas.1405222111

87. Prechtl J, Kneip C, Lockhart P, Wenderoth K, Maier UG. Intracellular spheroid bodies of Rhopalodia gibba have nitrogen-fixing apparatus of cyanobacterial origin. Mol Biol Evol. 2004;21(8):1477-1481. http:// dx.doi.org/10.1093/molbev/msh086

88. Cavalier-Smith T, Lee JJ. Protozoa as hosts for endosymbioses and the conversion of symbionts into organelles. J Protozool. 1985;32(3):376379. http://dx.doi.org/10.1111/j.1550-7408.1985.tb04031.x

89. Theissen U, Martin W. The difference between organelles and 
endosymbionts. Curr Biol. 2006;16(24):R1016-R1017. http://dx.doi. org/10.1016/j.cub.2006.11.020

90. Bhattacharya D, Archibald JM. The difference between organelles and endosymbionts - response to Theissen and Martin. Curr Biol. 2006;16(24):R1017-R1018. http://dx.doi.org/10.1016/j.cub.2006.11.021

91. Bodył A, Mackiewicz P, Stiller JW. The intracellular cyanobacteria of Paulinella chromatophora: endosymbionts or organelles? Trends Microbiol. 2007;15(7):295-296. http://dx.doi.org/10.1016/j.tim.2007.05.002

92. Bodył A, Mackiewicz P, Gagat P. Organelle evolution: Paulinella breaks a paradigm. Curr Biol. 2012;22(9):R304-R306. http://dx.doi. org/10.1016/j.cub.2012.03.020

93. Wernegreen JJ. Strategies of genomic integration within insectbacterial mutualisms. Biol Bull. 2012;223(1):112-122.

94. Nakabachi A, Ishida K, Hongoh Y, Ohkuma M, Miyagishima SY. Aphid gene of bacterial origin encodes a protein transported to an obligate endosymbiont. Curr Biol. 2014;24(14):R640-R641. http:// dx.doi.org/10.1016/j.cub.2014.06.038

95. Archibald JM. Back to the future. In: One plus one equals one: symbiosis and the evolution of complex life. Oxford: Oxford University Press; 2014. p. 157-172.

96. Reyes-Prieto M, Latorre A, Moya A. Scanty microbes, the "symbionelle" concept. Environ Microbiol. 2014;16(2):335-338. http://dx.doi. org/10.1111/1462-2920.12220

97. van de Velde W, Zehirov G, Szatmari A, Debreczeny M, Ishihara $\mathrm{H}$, Kevei Z, et al. Plant peptides govern terminal differentiation of bacteria in symbiosis. Science. 2010;327(5969):1122-1126. http:// dx.doi.org/10.1126/science.1184057

98. Login FH, Balmand S, Vallier A, Vincent-Monegat C, Vigneron A, Weiss-Gayet M, et al. Antimicrobial peptides keep insect endosymbionts under control. Science. 2011;334(6054):362-365. http://dx.doi. org/10.1126/science.1209728

99. Koga R, Meng XY, Tsuchida T, Fukatsu T. Cellular mechanism for selective vertical transmission of an obligate insect symbiont at the bacteriocyte-embryo interface. Proc Natl Acad Sci USA. 2012;109(20):E1230-E1237. http://dx.doi.org/10.1073/ pnas.1119212109
100. Nikoh N, McCutcheon JP, Kudo T, Miyagishima SY, Moran NA, Nakabachi A. Bacterial genes in the aphid genome: absence of functional gene transfer from Buchnera to its host. PLoS Genet. 2010;6(2):e1000827. http://dx.doi.org/10.1371/journal.pgen.1000827

101. Nikoh N, Nakabachi A. Aphids acquired symbiotic genes via lateral gene transfer. BMC Biol. 2009;7(1):12. http://dx.doi. org/10.1186/1741-7007-7-12

102. Moran NA, McCutcheon JP, Nakabachi A. Genomics and evolution of heritable bacterial symbionts. Annu Rev Genet. 2008;42(1):165-190. http://dx.doi.org/10.1146/annurev.genet.41.110306.130119

103. Moya A, Peretó J, Gil R, Latorre A. Learning how to live together: genomic insights into prokaryote-animal symbioses. Nat Rev Genet. 2008;9(3):218-229. http://dx.doi.org/10.1038/nrg2319

104. Nowack ECM, Grossman AR. Evolutionary pressures and the establishment of endosymbiotic associations. In: Bakermans $\mathrm{C}$, editor. Microbial evolution under extreme conditions. Berlin: De Gruyter; 2015 (in press). p. 223-246.

105. Nowack ECM, Melkonian M. Endosymbiotic associations within protists. Phil Trans R Soc B. 2010;365(1541):699-712. http://dx.doi. org/10.1098/rstb.2009.0188

106. McCutcheon JP, McDonald BR, Moran NA. Origin of an alternative genetic code in the extremely small and GC-rich genome of a bacterial symbiont. PLoS Genet. 2009;5(7):e1000565. http://dx.doi.org/10.1371/ journal.pgen. 1000565

107. McCutcheon JP, Moran NA. Parallel genomic evolution and metabolic interdependence in an ancient symbiosis. Proc Natl Acad Sci USA. 2007;104(49):19392-19397. http://dx.doi.org/10.1073/ pnas.0708855104

108. Nakabachi A, Yamashita A, Toh H, Ishikawa H, Dunbar HE, Moran NA, et al. The 160-kilobase genome of the bacterial endosymbiont Carsonella. Science. 2006;314(5797):267-267. http://dx.doi.org/10.1126/ science. 1134196

109. Tamames J, Gil R, Latorre A, Peretó J, Silva FJ, Moya A. The frontier between cell and organelle: genome analysis of Candidatus Carsonella ruddii. BMC Evol Biol. 2007;7(1):181. http://dx.doi. org/10.1186/1471-2148-7-181 